\title{
Effect of spa treatment and speleotherapy in the treatment of chronic obstructive pulmonary disease - a pilot study
}

\author{
L. Kendrovái, P. Takáč², A. Kubincová², W. Mikul'áková³, \\ P. Nechvátal ${ }^{3}$
}

Original Articles

${ }^{1}$ University of Prešov in Prešov, Faculty of Health Care, Department of Physiotherapy, Slovak Republic and UPJŠ, Faculty of Medicine, Department of Public Health, Slovak Republic

2 Pavol Jozef Šafárik University, Faculty of Medicine, Louis Pasteur University Hospital in the Košice, Department of Physiotherapy, Balneology and Medical Rehabilitation, Slovak Republic

${ }^{3}$ University of Prešov in Prešov, Faculty of Health Care, Department of Physiotherapy, Slovak Republic

\section{Correspondence to:}

University of Prešov, Faculty of health care disciplines, Department of Physiotherapy,

Partizánska 1,080 01 Prešov, Slovak Republic; e-mail: Lucia.Kendrova@unipo.sk

Submitted: 6.5.2016 Revised: 11.6.2016 Accepted: 5.8.2016

\section{Reviewers:}

S. Subramanian, president of SAAaRMM, Kuala Lumpur, Malaysia

I. Bartosovic, Tropical international team of St. Elizabeth, Slovak Republic

\section{Key words:}

Chronic obstructive pulmonary disease, Speleotherapy, spa treatment, quality of life, anxiety, depression.

CSWHI 2016; 7(2): 7-15 @ 2016 Clinical Social Work and Health Intervention

\section{Abstract:}

Objective: The aim of our research was to determine the effect of Speleotherapy on the quality of life, anxiety and depression in patients with COPD. Design: Pilot study. Participants: The 128 patients with CPOD participated in the study (average age 64.05), examined during a spa treatment in a sanatoriums in the High Tatras. The experimental group (29 patients) completed spa treatment and Speleotherapy in the Belianska Cave. The control group (99 patients) completed a spa treatment without Speleotherapy. All patients were examined on admission and discharge, for an average 20-day treatment stay. Methods: They 
were evaluated on the basis of the quality of life (SGRQ), Beck and Zung, the Spirometric Test (FEV1 and FEV1/FVC) and the 6-minute Walk Test. Results: After the treatment, concerning the patients of the experimental group we recorded that within the evaluation of quality of life there was significant improvement in symptoms $(\mathrm{p}<0.05)$. There was also statistically significant improvement in anxiety and the six-minute Walk Test $(\mathrm{p}<0.05)$. Conclusion: The pilot study shows that spa treatment along with Speleotherapy improves the quality of life and anxiety in patients with COPD. However, there is a need for prolonged study with more patients in order to demonstrate the effectiveness of this therapy.

\section{Introduction}

Lung diseases are currently a serious problem worldwide for their high prevalence, morbidity and mortality, as well as the negative impact on the patient's quality of life. GOLD (Global Initiative for Chronic Obstructive Lung Disease) ${ }^{1}$ defines chronic obstructive pulmonary disease (COPD) as a treatable disease that can be prevented, although it has some serious extra-pulmonary consequences. Pulmonary disease manifestations are characterized by airflow limitation that is not fully reversible. It is usually progressive and often associated with an abnormal inflammatory response of the lungs to inhaled noxious particles and gases. COPD is a respiratory disorder, which is currently one of the leading causes of chronic morbidity and mortality ${ }^{2}$. It is characterized as a very progressive and irreversible pulmonary obstruction with dyspnea ${ }^{3}$.

Each patient who becomes breathless when Walking or at an easy pace on level ground, should be provided with rehabilitation, which should particularly include resistance training and daily activities, further respiratory gymnastics, respiratory physiotherapy, positional drainage and physical therapy, as well as nutritional support.
Rehabilitation improves the quality of life, participation in daily activities, load tolerance and relieves shortness of breath and fatigue ${ }^{1,3,4,5}$. According to the ATS/ERS pulmonary rehabilitation is a multidisciplinary and comprehensive intervention for patients with chronic lung disease in which symptoms predominate and often limit daily activities. It is part of an individual patient's treatment and is designed to optimize functional status, enhanced participation in physical and social activities, improve the quality of life and reduce healthcare costs by stabilizing or reversing the systemic manifestations of the disease ${ }^{6}$.

Speleotherapy is a treatment method, using the specific and unique features of the environment, especially particulate matter contained in the air of underground spaces, mostly karst caves, in the treatment of chronic and allergic respiratory diseases. Speleotherapy in the treatment of COPD is recommended by the broader community ${ }^{7}$ and is often described as a verifiably reviewed treatment method for people with the disease. In Eastern Europe, natural salt caves were used for the relief of respiratory symptoms ${ }^{8}$. This therapy is known as Speleotherapy, in which a natural salt cave 
is used as climate therapy for poor health ${ }^{9}$. The unique properties of the micro-climate in caves are the constant air temperature of moderate to high humidity, the presence of fine aerosol elements, as well as the lack of pollutants and pollen in the air ${ }^{10}$. Nowadays, salt caves are used for treatment at health centers in Austria, Poland, Slovakia, Romania, Azerbaijan, Kyrgyzstan, Russia and Ukraine $^{11}$.

Spa Therapy. Spa Medicine includes all medical activities derived from the tradition of spas based on the scientific knowledge of prevention, health promotion, treatment and rehabilitation ${ }^{12}$. The benefits of spas are therefore still under discussion, although natural healing is used for therapeutic purposes ${ }^{13}$. Related to this point is also the particular climatic effects and psychosomatic effects associated with temporary changes in the family and working environment. Due to complexity various forms of physical therapy are also used.

The climactic conditions and solar radiation also potentiate the effects of these procedures. Regarding the effect of spa treatments, there are also other important social and psychological factors, such as social networking, leisure and cultural activities, as well as implementation of various recreational and sports activities, a pleasant atmosphere and natural environment conducive to health ${ }^{14}$.

\section{Groups and methods}

Our pilot study, which ran from $\mathrm{Au}-$ gust to December 2014, was attended by 128 patients ( 87 men and 41 women) with a mean age of 64.05 years $(\mathrm{SD} \pm 11.29)$. The actual research was conducted in three spa facilities located in the Slovak part of the High Tatras, in Sanatoriu Tatranská Kotlina, n.o., Sanatoriu Dr. Guhra n.o. Tatranská Polianka and in the Nová Polianka
Highly-Specialized Institute for Lung Diseases. Patients were informed of the examination and signed a consent form. The spa treatment lasted 19 days $(\mathrm{SD} \pm 1.5)$ and contained 5-6 treatments, 5 times a week. Patients underwent climatic therapy, respiratory physiotherapy, physical therapy and hydrotherapy. The experimental group consisted of 29 patients who underwent spa treatment and Speleotherapy 4 times a week for 50 minutes, that is 10 to 12 times during the stay. The Speleotherapy was performed in the Belianska Cave and combined with breathing gymnastics. The control group consisted of 99 patients who completed just a spa treatment without Speleotherapy. The patients were examined at the beginning and end of the spa stay. The examination consisted in assessing the Saint George's Respiratory Questionnaire (SGRQ). We further evaluated the Anxiety and Depression Questionnaires by Beck and Zung. Through the Spirometry Test we evaluated FEV 1 and $\mathrm{FEV}_{1} / \mathrm{FVC}$. Part of the examination was also a 6-minute Walk Test (6MWT).

The obtained results were statistically evaluated through the SPSS Program, Version 18 . We used a paired t-test.

\section{Saint George's Respiratory Question-} naire (SGRQ) was designed to measure the quality of life in patients with COPD. The questionnaire, in addition to an overall score assesses the health of the patient through three aspects: symptoms, activity and impact of the disease. The resulting scores are real numbers in the range of $0-100$, the higher score indicating a worse condition for this aspect. The first component symptom score displays the frequency and strength of respiratory complaints such as coughing, wheezing, and the strength of the number of seizures (Questions 1-8). The score activity relates to activities that are limited by dyspnea (Questions 11 and 15). The score impact (activity) shows the 
aspects related to social function and psychological problems caused by respiratory disease (Questions 10, 12, 13, 14, 16 and 17). In the final step, the total is calculated, which serves to summarize the impact of the disease on general health. The worst possible score for symptoms is 662.5, for activity 1,209.1, and for impact of disease $2,117.8$, for a total score of $3,989.4^{15}$.

BAI - Beck Anxiety Inventory According to the Likert Scale of 1-4, where 1 means not at all and 4 strongly (I'm barely holding on). The total score ranges from 0 to 63 . The results are interpreted as: $0-7$ : free of signs of anxiety, 8-15: moderate anxiety: 16-25: moderate anxiety 26-63: severe anxiety. It contains 13 items and is suitable for the general population ${ }^{16}$.

\section{SDS - Zung's Self-Rating Depression}

Scale is intended for the general public regarding the presence of depression. According to the Likert Scale of 1-4, where 1 means sometimes or rarely and 4 very often or always. The results (SDS Index Score) are interpreted as follows: less than 50: normal, no sign of depression, 50-59: signs of minimal or mild depression, 60- 69: moderate to very clearly expressed depression, 70 and over: severe or extremely severe depression $^{17}$.

6-minute Walk Test (6-MWT). The American Thoracic Society says that the 6-MWT does not allow the quantification of the factors limiting physical activity and does not provide an indication of maximum oxygen consumption during exercise. 6-MWD correlates well with the quality of life, better reflects the change in dyspnea after therapeutic interventions, and in patients with COPD after the completion of pulmonary rehabilitation is correlated with life expectancy. Evaluation test - the normal value on the basis of studies is considered distance $>500 \mathrm{~m}$ for women and $>600$ for men. Accounting for the age of the patient can be expressed by the following formula: $6 \mathrm{MWD}=800-(5.4 \mathrm{x}$ age $)$. For COPD patients there is given the value of 50 to 55 $\mathrm{m}^{18,19,20}$.

In the Spirometry Test we focused on the presence of a post bronchodilator, where according to GOLD $\mathrm{FEV}_{1}<80 \%$, the predicted value in combination with $\mathrm{FEV}_{1} / \mathrm{FVC}<70 \%$ confirms the presence of bronchial restrictions. $\mathrm{FEV}_{1}$ is the volume of air exhaled in one second and FVC is the forced vital capacity, i.e. the volume of air forcibly blown out after full inspiration $^{1,21}$.

\section{Results}

To evaluate the quality of life, the Saint George's Respiratory Questionnaire (SGRQ) was used. The results of the comparison of the experimental and control groups regarding quality of life confirm one component, namely the symptoms that display the frequency and strength of respiratory complaints such as coughing, shortness of breath, number of seizures and strength on the level of statistical significance $\mathrm{p}=0.014$ (Table 1).

Despite improvements in spirometry in the $\mathrm{FEV}_{1}$ and $\mathrm{FEV}_{1} / \mathrm{FVC}$, we did not record a statistically significant difference in spirometry $(p<0.05)$. Spirometry was improved in respondents who underwent spa treatment together with Speleotherapy in the $\mathrm{FEV}_{1}$ parameter at the end of treatment by $4.07 \%$ and $\mathrm{FEV}_{1} / \mathrm{FVC}$ by $4.26 \%$. In respondents who completed only spa treatment there was spirometry improvement in $\mathrm{FEV}_{1}$ at the end of treatment by $2.54 \%$ and $\mathrm{FEV}_{1} / \mathrm{FVC}$ $3.21 \%$. A statistically significant difference $(p=0.031)$ was recorded through the Beck Anxiety Inventory at the end of treatment. Respondents who completed spa treatment along with Speleotherapy suffered only mild anxiety. A statistically significant difference 
Tab. 1 SGRQ comparison of quality of life SGRQ

\begin{tabular}{|l|c|c|c|c|c|c|}
\hline & Group & $\mathbf{N}$ & Mean & SD & t & p \\
\hline \multirow{2}{*}{ Symptoms score } & experimental & 29 & 31.50 & 16.72 & 2.513 & $\mathbf{0 . 0 1 4}$ \\
\cline { 2 - 7 } & control & 63 & 41.53 & 18.25 & & \\
\hline \multirow{2}{*}{ Activity score } & experimental & 29 & 46.47 & 17.39 & 1.560 & 0.122 \\
\cline { 2 - 7 } & control & 63 & 51.94 & 14.74 & & \\
\hline \multirow{2}{*}{ Impacts score } & experimental & 29 & 29.20 & 21.30 & 0.533 & 0.595 \\
\cline { 2 - 7 } & control & 63 & 31.49 & 18,20 & & \\
\hline \multirow{2}{*}{ Total score } & experimental & 29 & 34.89 & 17.64 & 1.277 & 0.205 \\
\cline { 2 - 7 } & control & 63 & 39.37 & 14.61 & & \\
\hline
\end{tabular}

${ }^{*} \mathrm{p}<0.05$, wherein a significant difference in the experimental group for symptoms

was observed in the evaluation of the 6MWT $(\mathrm{p}=0.004)$. Respondents who completed spa treatment along with Speleotherapy passed at the end of treatment by 26.56 meters more than before, while respondents who completed only spa treatment passed by 24.13 meters more (Table 2). at night. In some cases, the significant decrease of flow of air can develop without the presence of a cough. Shortness of breath is the reason most patients seek medical attention and is a major cause of disability and anxiety associated with the disease $\mathrm{e}^{1,22}$.

According to the ATS/ERS ${ }^{6}$ pulmonary

Tab. 2 Comparison of Spirometry, Depression, Anxiety \& 6-minute Walking test

\begin{tabular}{|l|c|c|c|}
\hline \multicolumn{1}{|c|}{ Analysis } & $\begin{array}{c}\text { Admission } \\
\text { Examination }\end{array}$ & Experimental group & Control group \\
\hline FEV $_{\mathbf{1}}$ & $65.06 \pm 22.17$ & $69.13 \pm 22.28$ & $73.44 \pm 23.40$ \\
\hline FEV $_{\mathbf{1}} / \mathbf{F V C}$ & $76.36 \pm 18.64$ & $80.62 \pm 17.28$ & $83.04 \pm 19.18$ \\
\hline Beck & $14.03 \pm 9.18$ & $8.00 \pm 5.02^{*}$ & $11.13 \pm 6.88$ \\
\hline Zung & $56.22 \pm 11.07$ & $49.41 \pm 8.08$ & $46.52 \pm 8.14$ \\
\hline 6-minute Walking test & $221.72 \pm 80.05$ & $248.28 \pm 84.81^{* *}$ & $320.00 \pm 118.24$ \\
\hline
\end{tabular}

Legend: FEV 1 - The volume of air exhaled in the first second of forced expiratory flow, FVC - Total forced lung capacity

$* \mathrm{p}<0.05$, wherein a significant difference in the experimental group regarding anxiety

** $p<0.005$, where there is a significant difference in the experimental group in the 6-minute Walk Test

\section{Discussion}

According to GOLD and WHO, a cough is usually the first sign of CPOD. Initially it may be intermittent, but later it is present every day, often throughout the day, rarely rehabilitation is multidisciplinary and comprehensive intervention for patients with chronic lung disease in which symptoms predominate, often limiting daily activities. It is part of an individual patient's treatment, and is designed to optimize functional status, 
enhance participation in physical and social activities, improve the quality of life and reduce healthcare costs by stabilizing or reversing the systemic manifestations of the disease $^{6,23}$. Puhan and Gimeno-Santos indicate that pulmonary rehabilitation has become an essential element in the care of patients with $\mathrm{COPD}^{24}$. Systematic evaluation has shown the large and important clinical effects of pulmonary rehabilitation in patients with COPD. Pulmonary rehabilitation leads to an improvement in several resulting areas, and plays a significant role for the patient, including dyspnea, exercise ability, health status and health care utilization ${ }^{25,26}$. The minimum length of time for an effective rehabilitation program is two months and should include the self-management of patients ${ }^{1}$.

To evaluate quality of life, we used the standard Saint George's Respiratory Questionnaire (SGRQ). Using the t-test, we compared whether respondents who completed a spa treatment along with Speleotherapy have a better quality of life. It confirmed one component, the symptoms displaying the frequency and strength of respiratory complaints - coughing, shortness of breath, number of seizures and the strength at the significance level of $\mathrm{p}=0.014$. Horvath ${ }^{9}$, Chervinskaya \& $\mathrm{Ziber}^{10}$ reported an improved quality of life in COPD patients after the completion of Speleotherapy and Halotherapy. Horváth confirmed that $90.4 \%$ of patients treated by Speleotherapy showed an improved clinical condition, compared to $72.8 \%$ in the control group. The authors found that clinical improvement enhances the quality of life of patients with COPD, thereby reducing exacerbations and hospitalization?.

It improves physical tolerance and reduces fatigue. Withers et al and Emery et al report that pulmonary rehabilitation improves depression and anxiety in patients with $\mathrm{COPD}^{27,28}$.

Despite improvements in spirometry in the $\mathrm{FEV}_{1}$ and $\mathrm{FEV}_{1} / \mathrm{FVC}_{\text {parameters, we re- }}$ corded a statistically significant difference in spirometry $(p>0.05)$. At the end of treatment the spirometry showed improvement in respondents who underwent a spa treatment together with Speleotherapy in the $\mathrm{FEV}_{1}$ parameter by $4.07 \%$ and $\mathrm{FEV}_{1} / \mathrm{FVC}$ by $4.26 \%$. At the end of treatment, for respondents who completed only the spa treatment, the spirometry showed an improvement in the $\mathrm{FEV}_{1}$ parameter of $2.54 \%$ and $\mathrm{FEV}_{1} / \mathrm{FVC}$ of $3.21 \%$. Horvath, in his studies, described improved airway function by measuring $\mathrm{FEV}_{1}$ before and after treatment. The mean $\mathrm{FEV}_{1}$ in the treated group $(\mathrm{n}=230)$ was improved from $1.47 \pm 0.631$ liters to $1.68 \pm 0.71$ liters. The respondents completed respiratory physical therapy, which included Speleotherapy. In the control group $(n=151)$ there was an improvement of $1.64 \pm 0.61$ liters to $1.67 \pm 0.68$ liters $^{9,10}$. Nurov, in his studies, reported improved immune function after completing Speleotherapy, but did not report specific tests on lung function in patients with COPD. He concluded that Speleotherapy improves the immunological status of patients with COPD, and consequently reduces the inflammatory process, particularly during exacerbations ${ }^{29}$.

A statistically significant difference $(\mathrm{p}=$ 0.031) was recorded in the Beck Anxiety Inventory at the end of treatment. Respondents who completed spa treatment along with Speleotherapy had moderate anxiety. Kunik et al in their study describes the improvement of quality of life, anxiety and depression $(p<0.005)$ after 8 weeks of Cognitive-Behavioral Therapy ${ }^{30}$.

A statistically significant difference was observed in the evaluation of the 6-minute Walk Test $(p=0.004)$. Respondents who completed spa treatment along with Speleotherapy passed at the end of treatment 26.56 meters more than before, while respondents who completed only spa treatment passed by 24.13 meters more. Leupold, in his study, 
examined 210 patients with COPD and investigated the effects of intensive 3-week outpatient pulmonary rehabilitation, focused on exercising lung capacity, dyspnea and improving quality of life. He made investigations before and after pulmonary rehabilitation and assessed physical activity with the 6MWT. The test results showed an improvement in the 6MWT of $(+39 \mathrm{~m}$, $\mathrm{p}<0001)$ following treatment and simultaneously reduced dyspnea in the 6MWT of $(-0.5, p<0.001)$. The improvement in all dimensions of the SF-36 reflects the improved quality of life after treatment $(\mathrm{p}<0.001)^{31}$. Takata et al found that spa treatment improved ventilation dysfunction and in the 6MWT the distance traveled by COPD patients increased ${ }^{32}$.

Dramsdahl, Harari \& Avriel et al described the term "Dead Sea Climatotherapy" including several therapeutic methodologies under the supervision of a physician: Heliotherapy, Balneotherapy, Hydrotherapy, Physiotherapy, Sports and Physical Education with the optimal use of unique climatic factors ${ }^{33,34,35}$. The Dramsdahl Study in Norway showed significant improvement in patients with COPD in health and the quality of life after completing Climatotherapy by the Dead Sea, describing their stay as a turning point in their history of the disease in their lifetime. Most patients were able to continue working, training or studying ${ }^{33}$.

\section{Conclusion}

As a partial department Speleomedicine can be found on the border of natural and medical sciences. It includes the creation and application of appropriate therapies. In Slovakia, it is carried out in various forms in natural caves. According to medical approaches and self-treatment in caves, besides Speleotherapy, climatic and reconditioning stays are also carried out. The condition and success guarantee of the cave treatment is so-called salt water aerosol, which is air with finely-dispersed components of the solid and liquid phases. In comparison with other studies, we found that regarding Speleotherapy, there are few studies that confirm the success or failure of therapy. This will reduce the potential evidence in support of this therapy. In our research, we found improvement in anxiety and an increase of the distance covered in the 6MWT after completing Speleotherapy with spa treatment.

\section{Declaration of interest}

The authors report no conflicts of interest. The authors alone are responsible for the content and writing of the paper.

\section{References}

1. RAHERISON C, GIRODET PO (2013) Global Initiative for Chronic Obstructive Lung Disease. Global strategy for the diagnosis, management and prevention of chronic obstructive pulmonary disease; [cited 2015 Jan 3]. Available from: //www. goldcopd.org/guidelines-global-strategyfor-diagnosism management. html Epidemiology of COPD In European Respiratory Review; 18(114), 213-21.

2. CELLI BR (2008) Update on the management of COPD. (2008) [cited 2014 Dec 19]. Available from: http://www.ncbi.nlm.nih. gov/pubmed/18574288.

3. NICI L et al (2006) American Thoracic Society/European Respiratory Society Statement on Pulmonary Rehabilitation. In: American Journal of Respiratory and Critical Care Medicine, 173, 2006, s. 13901413.

4. NICI L, DONNER C, WOUTERS E, ZUWALLACK R, AMBROSINO N, BOURBEAU J et al (2006) Pulmonary Rehabilitation Writing Committee American Thoracic Society/European Respiratory Society 
Statement on Pulmonary Rehabilitation. In: American Journal of Respiratory and Critical Care Medicine, 2006, 173: 1390-1413.

5. RICE, KL, DEWAN, N, BLOOMFIELD, HE et al (2010) Disease management program for chronic obstructive pulmonary disease: a randomized controlled trial. $\mathrm{In}$ : Am J Respir Crit Care Med. 2010 [cited 2015 Jan 1]. Available from: http://www.ncbi.nlm. nih.gov/pubmed/20075385.

6. SPRUIT M A, SINGH S J, GARVEY CH, ZUWALLACK R, NICI L et al (2013) An Official American Thoracic Society/European Respiratory Society Statement: Key Concepts and Advances in Pulmonary Rehabilitation.. [cited 2015 February 9]. Available from: http://www.thoracic.org/statements/ resources/copd/PRExecutive_Summary 2013.pdf.

7. RASHLEIGH R, SMITH S MS, ROBERTS NJ (2014) A review of Halotherapy for chronic obstructive pulmonary disease.. [cited 2014 Dec 1]. Available from: http:// www.google.sk $/ 1$ ? sa $=$ t\&rct $=j \& q=e d=0 C$ CEQFjAA\&url=http $\% 3 \mathrm{~A} \% 2 \mathrm{~F} \% 2 \mathrm{~F}-$ Ww w.s.m\%2F getfile.p\%3FfileID\%3D19102\&ei=NKvhVPqOD9PZatecgPAD\&usg=AFQjCNFCHdpIETtZ9RnZG80km_8g\&sigVv8U81GFleQA\&b$\mathrm{vm}=\mathrm{bv} .85970519, \mathrm{~d} . \mathrm{d} 2 \mathrm{~s}$.

8. GRIMSHAW, T (2012) Salt Therapy (2012 [cited 2014 Dec 1]. Available from: http://aca. ninemsn.com.au/article/8472866/salt-therapy.

9. HORVATH T (1968) Speleotherapy: a special kind of Climatotherapy, its role in respiratory rehabilitation. Int Rehabil Med. 1986;8:90-92.

10. CHERVINSKAYA AV, ZIBER NA (1995) Halotherapy for treatment of respiratory diseases. J Aerosol Med. 8:221-232.

11. CHERVINSKAYA, AV (2003) Halotherapy of respiratory diseases. Physiotherapy, Balneology and Rehabilitation; 6:8-15.

12. GUTENBRUNNER C, BENDER T, CANTISTA P, KARAGÜLLE Z (2010) A proposal for a worldwide definition of health resort medicine, balneology, medical hydrology and climatology. In: Int J Biometeorol; 54(5): 495-507.

13. ROVENSKÝ J, PAYER J, CLAGUE RB et al (2009) Dictionary of Rheumatic Disease. Wien, Springer Verlag, 23.

14. CIMBIZ A, BAYAZIT V, HALLACELI H, CAVLAK U (2005) The effect of combined therapy (spa and physical therapy) on pain in various chronic diseases. In Complementary Therapies in Medicine: Elsevier,. ISSN 0965-2299, č.13. Str. 244-250.

15. JONES P (2008) St. George's respiratory questionnaire for COPD patients (SGRQ-C) manual London: Division of Cardiac and Vascular Science St George's, University of London [cited 2014 Dec 11]. Available from: http://www.healthstatus.sgul.ac.uk/SGRQ download/SGRQC\%20Manual\%202008. pdf.

16. BECK AT et al (1988) An Inventory for measuring clinical anxiety: Psychometric properties. Journal of Consulting and Clinical Psychology. Vol. 56, no.6, p. 893-897.

17. ZUNG WK (1965) A Self-rating Depression Scale. Archives of General Psychiatry. 1965, Vol. 12, no. 1, p. 63-70.

18. American Thoracic Society (2002) ATS Statement: Guidelines for the Six-Minute Walk Test. [cited $2014 \mathrm{dec}$ 14]. Available from: http://www.thoracic.org/statements/resources/pfet/sixminute.pdf.

19. WEISS RA et al (2000) Six minute Walk Test in severe COPD: reliability and effect of Walking course layout and length. Paper presented at ACCP Conference; Sept 2000; San Francisco.

20. CHLUMSKÝ J (2003) Standard pro šestiminutový test chưzí. 2003. [cited 2014 Sec 28]. Available from: http://www.pneumologie.cz/odborne/doporucene-postupy.php

21. GOLD (2003) Global Initiative for Chronic Obstructive Lung Disease, updated. 2007. [cited 2014 dec 28]. Available from: http:// www.goldcopd.com/Guidelineitem.as$\mathrm{p} ? 11=2 \& 12=1 \&$ int $\mathrm{Id}=2003$. 
22. World Health Organization (2009) Global surveillance, prevention and control of CHRONIC RESPIRATORY DISEASES. A comprehensive approach. Switzerland. 2007. [cited 201412 28]. Available from: http://www.who.int/gard/publications/ GARD Manual/en/.

23. HODGKIN JE, BARTHOLOME RG, CONNORS GL (2009) Pulmonary rehabilitation. St. Luis. Mosby.

24. PUHAN MA, GIMENO-SANTOS E (2011) Pulmonary rehabilitation following exacerbations of chronic obstructive pulmonary disease (Review). The Cochrane Collaboration and published in The Cochrane Library. [cited 2014 Dec 28]. Available from: http://summaries.cochrane.org/CD005305 /pulmonary-rehabilitation-for-people-who-have-been-in-hospital-with-an-exacerbation-of-chronic-obstructive-pulmonary-disease.

25. CELLI BR et al Standards for the diagnosis and treatment of patients with COPD: a summary of the ATS/ERS position paper 2004. [cited 2014 Dec 8]. Available from: http://erj. ersjournals. com/content/23/6/932.full.

26. LACASSE Y, Wong E et al (1996) Meta-analysis of respiratory rehabilitation in chronic obstructive pulmonary disease. [cited 2014 Dec 8]. Available from: http:// www.luzimarteixeira.com.br/wp-content/ uploads/2009/06/art_lacasse-e-col-1996meta-analysis-of-respiratory-rehabilitation-copd.pdf.

27. KOHÚTIK NJ, RUDKIN ST, WHITE RJ (1999) Anxiety and depression in severe chronic obstructive pulmonary disease: the effects of pulmonary rehabilitation. J Cardiopulm Rehabil.19:362-5.

28. EMERY CF, SCHEIN RL, HAUCK ER, MACINTYRE NR (1998) Psychologické a kognitívne výsledky randomizovanej štúdii s cvičením u pacientov s chronickou obštrukčnou chorobou pl'úc zdravie Psychol 17: 232-40.

29. NUROV I (2010) Immunologic features of
Speleotherapy in patients with chronic obstructive pulmonary disease. Medical and Health Science Journal. 2:44-47.

30. KUNIK ME, Veazey C, Cully JA, Souchek J, Graham DP, Hopko D et al (2008) COPD education and cognitive behavioral therapy group treatment for clinically significant symptoms of depression and anxiety in COPD patients: a randomized controlled trial. [cited 2014 Dec 19]. Available from: http://www. pulib.sk: 2088/w/204500266/13CFD01DF4C20534B6E/1?Accountid=14716\#

31. LEUPOLDT A.,Hahn E et al (2008). Effects of 3-week Outpatient Pulmonary Rehabilitation on Exercise Capacity, Dyspnea, and Quality of Life in COPD. [cited 2014 Dec 19]. Available from: http://www.pulib. sk:2088/docview/231707084/13C9F2EB 52068EF0AE2/2?accountid=14716].

32. TAKATA S, ASHID, K, HOSAKI Y et al (2008) Effects of spa therapy on the six-minute Walk Test in patients with chronic obstructive pulmonary disease. [online]. 2008. [cited 2014 Dec 19]. Available from: http://scholar.google.sk/r?hl=en\&q=TAKATA $\% 2 \mathrm{C}+\mathrm{S} . \% 2 \mathrm{C}+\mathrm{ASHIDA} \% 2 \mathrm{C}+\mathrm{K}$. $\% 2 \mathrm{C}+\mathrm{HOSAKI} \% 2 \mathrm{C}+$ Y. +et.+al.+Effects + of + spa + therapy + on + the + sixminute +Walk+test + in + patients + with + chron$\mathrm{ic}+$ obstive + pulmonary + disease. $+\& b t-$ $\mathrm{nG}=$ \&as_sdt $=1 \% 2 \mathrm{C} 5$ \&as_sdtp $=$

33. DRAMSDAHL E (2012) Multidisciplinary Rehabilitation and Climatotherapy for Chronic Diseases at the Dead Sea. Anales de Hidrología Médica Vol. 5, Núm. 1, 53-63. ISSN 1887-0813.

34. HARARI M, DRAMSDAHL E (2011) Multidisciplinary rehabilitation at the Dead Sea. Norway Medical Association. Indremedisineren. Jun; 39-41.

35. AVRIELL A, FUCHS L, PLAKHT Y et al (2011) Quality of life at the dead sea region: the lower the better? an observational study. [online].[cited $2014 \mathrm{dec}$ 19]. Available from: http:/www.ncbi.nlm.nih.gov/pmc/articles/ PMC3123541/. 